\title{
Learning Resource Centers: Adequacy and Relevance of Resources in Public Primary Teacher Training Colleges in Kenya.
}

\author{
Kosgei K. Zachariah \\ Moi University, School of EducationP.O Box 3900Eldoret, Kenya
}

\begin{abstract}
The purpose of this study was to investigate the adequacy and relevance of resources that are in public primary teachers training colleges in Kenya. It was guided by three objectives namely: to determine whether the materials available are adequate and relevant, to establish whether the materials are well maintained and to find out whether there is enough space in the learning resource centers in PPTTCs in Kenya. The study was carried out in Tambach Teachers Training College, Keiyo district, Rift Valley province of Kenya. This was a case study design and the target population was 1121. Data was collected and analyzed using descriptive statistics. The study revealed that there were inadequate relevant materials in the LRC such as course books used in both college classes and teaching practice in various departments, syllabuses, catalogues, computers, educational journals and other publications. This was attributed to poor planning of replenishment of LRC materials (low budgetary allocation to LRC) and the fact that tutors were not involved in sourcing of LRC materials. The findings point to the fact that the materials in the LRC are well maintained and that there is adequate space. The study will enhance the effective use of the learning resource centre at Tambach Teachers Training College and possibly all the TTCs in Kenya.
\end{abstract}

\section{INTRODUCTION}

The prime concern of a government in most countries, Kenya included is the establishment of information institutions charged with the responsibility of determining the information needs of the people. To provide efficient education and training services, the capacity and skills of staff in the various offices and organizations involved should be commensurate with the tasks they perform. Good management in education must aim at the improvement of the performance of the education system to make it more efficient in its utilization of available resources (Farrant, 1980).

One of the most urgent demands since independence has been to improve the education system in Kenya, and pertinent to this is the improvement in the quality of teachers. To satisfy these needs, the idea of learning resource centers was mooted in the late seventies. In primary teachers training colleges, the main purpose of a learning resource centre is to produce and make available hardware and software materials, lecture and viewing rooms, stores and reading booths. They also exist to promote the use of electronic information resources and other valuable resources for learning so that improved conditions for learning are generated. Oluoch (2000) noted that LRCs in Public Teachers Training Colleges face serious problems of acquisition and maintenance of equipments and materials. Educational resources are considered as most important element of LRC and without it the centre cannot achieve its main role. Where resources are available, the teaching and learning resources ceases to be useful in cases where they are not availed to users who need to use or borrow them. As much as storage is important ensure that the resources are accessible when needed

All the Public Primary Teachers Training colleges have resource centers. They however face serious problems of acquisition and maintenance of the equipment and materials and lack of adequate personnel to run them. Some have reverted to the status of simple libraries with just a few books, most of them not even relevant to the present training of teachers (Oluoch, 2002). Because many Teachers Training Colleges do not have well stocked LRCs, some extracts from books, educational journals and other publications have been reproduced in order to provide materials for analysis, discussion and comments in the hope that these will encourage students to make greater use of reference books and research materials for themselves (Farrant, 1980).

Learning resource centers are an extension of the library idea in that they offer borrowing facilities to students for books and non-book materials. In the latter category are included such things as pictures, charts, posters, films, slides, filmstrips, and all types of recorded materials. In addition resource centers often provide technical services that individual teachers or institution cannot afford but which greatly assist them in the production of their own teaching materials. Resource centers are of immediate help to teachers when they exist at institutional level with all the resources catalogued and stored for easy access (Baird, 1994).

According to Baird (1994) the following are functions of LRCs:- Establishing and maintaining a collection of reference books, providing answers to simple factual reference books, directing users who need research information to possible sources of information, publishing new issues of periodicals either through the 
display of new issues or communication directly with users, routing information sources to users whose interest are known particularly in research and special libraries, directing information seekers to relevant information in the library or obtaining such information from other libraries using their knowledge of their collections and conducting comprehensive literature searchers based on users request.

Commenting on the need for efficiency, Nafukho, (2000: 13) noted that given the scarce resources allocated to the education sector, there is a great need for education institutions to be both internally and externally efficient. The LRC is one of the most important input into the education system and therefore efficient management and utilization of teachers is critical to the quality of learning outcomes. Both Umans, (1972) and Coombs (1976) agree that for effective management, there must be clearly stated objectives. According to Benkley (2006) LRCs works under the following objective: a LRC ought to be seen as a reference of information and communication, it is to be seen as a learning and teaching resources centre for lecturers, students and the college community as a whole. It enhances ICT application in the library services, it utilizes to maximum levels the available library space, improving the status of strategic LRC resources and involving measures for improving LRC budgeting and users charges.

According to a research on PTTC in Kenya by (UNESCO, 2008) the ICT policy and ICT master plan for TTCs need to be in place, and to be oriented towards institutional building especially as related to research, teaching and outreach activities. This organization further noted that significant steps forward have, not been made in building and promoting the TTCs' ICT resources. The researcher noted that the visited teacher training colleges have LRCs with a collection of some old volumes.

\section{OBJECTIVES}

1. To determine the adequacy and relevance of LRC materials.

2. To establish the maintenance of materials in LRC's.

3. To determine the availability of space to LRC users.

\section{FINDINGS}

Availability of Learning Resources in the LRC

Several variables were used to ascertain the availability and relevance of materials in the LRC. The study wanted to find out whether there was enough room for users in the LRC. It also wanted to find out if materials in the LRC were well kept and availed to users when needed. The variety of resources available in the LRC was also to be established. Students' awareness on the availability of materials, especially short loan materials was to be investigated. The findings were presented in the tables and graphs under the themes below.

Adequacy and Relevant of LRC Materials to the Needs of the Users

Focus was on the materials in the LRC, views were sought from the students, tutors and LRC staff on the adequacy and relevance of materials available for their use in the LRC. Their responses were as follows:

Table 1.1 LRC Materials are Adequate and Relevant to Needs of Users

\begin{tabular}{|l|l|l|}
\hline Response & Frequency & Percentage \% \\
\hline Agree & 101 & 33.7 \\
\hline Undecided & 11 & 3.7 \\
\hline Disagree & 188 & 62.6 \\
\hline Total & $\mathbf{3 0 0}$ & $\mathbf{1 0 0 . 0}$ \\
\hline
\end{tabular}

From table $1.162 .6 \%$ of respondents disagreed, and $33.7 \%$ agreed that the materials in the LRC were adequate and relevant to needs of users $3.7 \%$ were undecided. In effect this implied that a good number of respondents did not find the LRC as a good source of materials relevant to their needs. Thirty three point seven percent of those who agreed could be the first year students who were still not conversant of the activities of the college.

Student respondents were asked to give their opinion on whether there was regular restocking of the LRC. Twenty three point three percent agreed, $44.7 \%$ disagreed while $32.0 \%$ were undecided. Lack of new arrival section in the LCRs could be the main reason why respondents could not respond well on this item. The researcher was of the assumption that there are areas of information in the LRC where users would find out information on new arrivals and material type population in the LRC. This could also imply that majority of the students are not aware of what takes places in the LRC in terms of new stocking, restocking and weeding of irrelevant or old materials which are out dated. Tutors who participated in the study were asked if they participated in procurement of LRC materials for their departments and if the materials they procured were availed on time. This was important to the research because the tutors are professionally obligated to be familiar with the latest relevant materials for their departments. The study found out that $66.7 \%$ of tutors did not order 
LRC material for their departments, while only $11.1 \%$ agreed that they ordered materials for their departments. Twenty point two percent fail to give their comments. Most of the tutors were of the view that ordering of LRC materials was the obligation of the HOD/HOS. The study sought to find out whether the tutors felt that there were enough materials for their departments in the LRC. These are presented in tale 4.8 it revealed that $16.7 \%$ were of the view that the materials were enough while $61 \%$ were of the contrary view. Those who disagree referred to lack of reference materials, primary course books for teaching practice students, a variety of audiovisual teaching and learning materials which were either lacking or had broken down. These are presented in the table 1.2 below.

Table 1.2 indicates the response on adequacy of LRC materials for each department at Tambach TTC.

Table 1.2 There are enough Materials for my Department at the LRC

\begin{tabular}{|l|l|l|}
\hline Response & Frequency & Percentage \% \\
\hline Agree & 3 & 16.7 \\
\hline Undecided & 4 & 22.2 \\
\hline Disagree & 11 & 61.1 \\
\hline Total & $\mathbf{1 8}$ & $\mathbf{1 0 0 . 0}$ \\
\hline
\end{tabular}

These finding from the tutors reinforced the student's views (Table 1.1), that indeed the material in the LRC were inadequate and some available materials may not be very relevant to the needs of LRC users. The relevance of materials was a result from comments on item number 9 on tutors questionnaires requiring tutors to state the challenges facing LRC users in Tambach TTC. The LRC staff conceded that indeed there was shortage of current material at the LRC. When asked to rate the stock at LRC, the staff at the LRC rated the stock as good. It was also noted that LRC materials were replenished yearly, and stock taking is also done yearly. From the questionnaires returned by the college administrators, it was noted that textbooks for all subjects were inadequate, while irrelevant material were more than adequate in the LRC. This includes old books, photocopiers, typewriters, charts, pamphlets, past papers etc. These findings clearly revealed that there was a shortage of materials at the LRC.

\section{MAINTENANCE OF MATERIALS AT THE LRC}

Well maintained materials are appealing to users. The research therefore wanted to determine whether in the judgment of the respondents, materials in the LRC were kept in good condition and availed to users when needed. Respondents were to state whether they strongly disagreed, disagreed, undecided, agreed or strongly agreed, that LRC materials were well kept. The results were presented in the Table 1.3 below.

Table 1.3: contain information on maintenance and availability of materials for users.

Table 1.3 LRC Materials are well Maintained and Available to Users

\begin{tabular}{|l|l|l|}
\hline RESPONSE & FREQUENCY & PERCENT \% \\
\hline strongly disagree & 64 & 21.6 \\
\hline Disagree & 38 & 12.8 \\
\hline Undecided & 14 & 4.7 \\
\hline Agree & 122 & 41.2 \\
\hline Strongly agree & 58 & 19.6 \\
\hline Total & 296 & 100.0 \\
\hline
\end{tabular}

From table 1.3 above, it was unmistakable that a remarkable $60.8 \%$ of respondents agreed that materials in the LRC were well maintained and available to users when needed, while only a paltry $34.4 \%$ disagreed. This demonstrated clearly that most users of the LRC were of the opinion that the materials available in the LRC were well maintained, signifying that these materials were likely to be appealing to users, and were up to the expected standard. Users therefore enjoyed using these materials or used them enthusiastically.

\section{ADEQUATE SPACE FOR ALL LRC USERS AT A GIVEN TIME}

The research sought to find out whether the space in the LRC was adequate for users at a given time. With assurance that there will be space, users may be motivated to visit the LRC. The pie chart (Figure1) below shows the answers of respondents when asked if they agreed or disagreed that there was enough space for users in the LRC. 
Figure 1Enough Space in LRC for Users

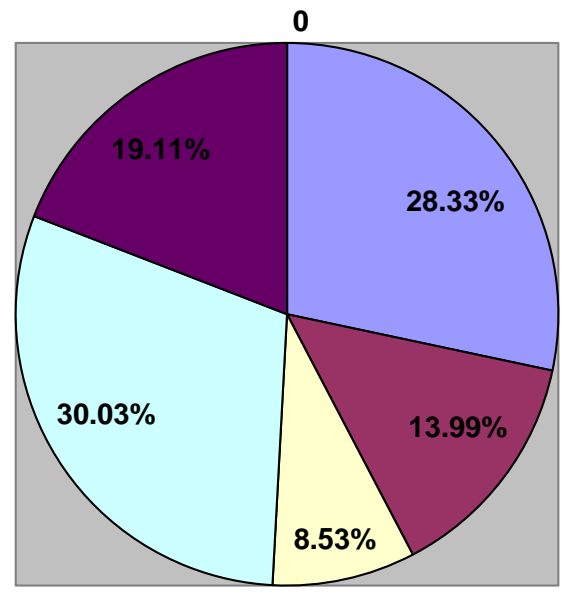

ธStrongly disagree

口Disagree

口Undicided

$\square$ Agree

$\square$ Strongly Agree

The pie chart clearly illustrated that majority of respondents (49\%) agreed that there was enough space in the LRC for users, as opposed to a cumulative $42 \%$ who disagreed. This finding was noteworthy in that it was evident that the optimum use of the LRC was not hindered by limited space in the LRC. Indeed $100 \%$ of LRC staff reported that there were times when the LRC was open and there were no users. The $42 \%$ of respondents who disagree could have referred to T.P and examination periods.

Asked about the lighting conditions in the LRC, majority of respondents $(66 \%)$ agreed that the LRC was well lit and therefore conducive for study. On availability of other services in the LRC, $53 \%$ of the respondents agreed that the LRC offered a variety of other services like micro teaching, photocopy and internet services. The need for the research to endeavor to establish the feedback of students on lighting of the LRC, and availability of other service was informed by the fact that these could be very important factors which could motivate students to visit the LRC. Majority of those who disagreed could have equated the cost incurred as a result of using such services to lack of them.

Table 1.4 is the summary of the findings on availability and adequacy of materials in the LRC at Tambach TTC. The mode, mean, medium and standard deviation has been used to analyze the satisfaction of the users.

Table 1.4 Summary: Availability and Adequacy of Materials

\begin{tabular}{|c|c|c|c|c|c|c|}
\hline \multirow[b]{2}{*}{ Variable } & \multicolumn{2}{|c|}{ TOTAL } & \multirow[b]{2}{*}{ Mean } & \multirow[b]{2}{*}{ Median } & \multirow[b]{2}{*}{ Mode } & \multirow[b]{2}{*}{ Std. Deviation } \\
\hline & Valid & Missing & & & & \\
\hline $\begin{array}{l}\text { Adequacy and relevancy of } \\
\text { materials in LRC }\end{array}$ & 300 & 0 & 1.61 & 1.00 & 1 & 1.190 \\
\hline $\begin{array}{l}\text { Presence of catalogues in the } \\
\text { LRC }\end{array}$ & 294 & 6 & 1.76 & 2.00 & 3 & 1.409 \\
\hline $\begin{array}{l}\text { Students awareness of short } \\
\text { loan materials }\end{array}$ & 296 & 4 & 1.37 & 1.00 & 0 & 1.347 \\
\hline $\begin{array}{l}\text { Librarians assist in locating } \\
\text { materials }\end{array}$ & 290 & 10 & 1.91 & 3.00 & 3 & 1.571 \\
\hline Materials are well maintained & 296 & 4 & 2.28 & 3.00 & 3 & 1.513 \\
\hline Enough staff at LRC & 296 & 4 & 2.26 & 3.00 & 3 & 1.541 \\
\hline $\begin{array}{l}\text { LRC materials maintained and } \\
\text { available }\end{array}$ & 298 & 2 & 1.71 & 1.00 & 0 & 1.486 \\
\hline $\begin{array}{l}\text { Electronic materials for micro } \\
\text { teaching available }\end{array}$ & 300 & 0 & 2.15 & 3.00 & 3 & 1.443 \\
\hline Enough space for users at LRC & 293 & 7 & 1.98 & 2.00 & 3 & 1.531 \\
\hline $\begin{array}{l}\text { Presence of exhibition room in } \\
\text { LRC }\end{array}$ & 291 & 9 & 1.74 & 2.00 & 0 & 1.387 \\
\hline Presence of other services & 300 & 0 & 2.17 & 3.00 & 3 & 1.440 \\
\hline Enough lighting at LRC & 294 & 6 & 2.77 & 3.00 & 3 & 1.171 \\
\hline
\end{tabular}


Table 1.4 shows the summary of responses to variables asked on adequacy and availability of LRC materials. The mean, mode, median and standard deviations are shown. The variables had been coded as follows: 0strongly disagree, 1-disagree, 2-undecided, 3-agree and 4 strongly agree. The mode gave a clearer picture of the responses. Since the maximum code (value) is 4 and the minimum is zero, a standard deviation of 1 was considered small, showing that the dispersion was small. From the summary table 1.4 it was noted at a glance that most respondents strongly disagreed that they were aware of short loan materials and an exhibition room in the LRC. The other variables in the table which were interpreted in the same way were librarians' assistance, enough staff and presences of other services in the LRC. Respondents were in agreement with the three items.

\section{CONCLUSION}

This research sought to establish the availability of learning resources in LRCs in PTTCs in Kenya. The study established that the LRC at Tambach T.T.C is not a good source of materials relevant to users' needs. The findings indicate that there is shortage of current materials at the LRC. Most of the book materials in the library section are either too old or are irrelevant to the teachers needs. Majority of the LRC materials are donations from donor countries whose curriculum may not match well with our system of education.

The study revealed that $62.6 \%$ of the student respondents and $61 \%$ of tutors respondents pointed out that the materials in the LRC were inadequate. Inadequacy here meant lack of relevant current materials which are expected to meet the needs of the users. Using observation checklist the research found out that there were a lot of old and outdated materials in the LRC. The study established that LRC materials were procured yearly and that was the main cause of the shortage of correct materials. Procurement is dependent on availability of funds. Due to lack of proper policy on the acquisition of LRC materials, the procurements depended on the good will of the college administration. Jones (2010) assets that if materials availed are not in demand and needed by the users of LRC, then the LRC becomes a warehouse of unwanted information. LRC users are a complicated group in that different users may need entirely different services from the LRC. Different occasions may need different materials and in different quantities. The procurement of LRC materials should be based on the activities of the users at different periods of the year. The study revealed that the inadequacy of materials could impact negatively on the desire of students to use the LRC. This apparent inadequacy of materials in the LRC at Tambach T.T.C, presents the LRC as falling far short of the idea of a learning resource centre as defined by Gorman and Howes, (1991).

On maintenance of LRC materials the study revealed that available materials in the LRC were properly maintained. The findings presented showed that $60.8 \%$ of the respondents agreed that LRC materials were indeed well maintained. Well maintained reading and electronic materials could be appealing to users. Poor maintenance could generate bad attitude from users and apathy towards the issue among users as noted by McColvin (1978).

Figure 1.1 revealed that majority of respondents $49.0 \%$ agreed that there was enough space in the LRC for users. The LRC staff indeed reported that there were instances when the LRC was opened and lacked users. The study concluded that space was not a hindrance to those who wanted to use the LRC. The LRC staff reported that there was a seating capacity of 150 in the LRC. The availability of space in the LRC could also be attributed to the coldness of the LRC, whereby users failed to go into the LRC for they have to remain without jackets and sweaters while inside.

\section{REFERENCES}

[1] Baird, N. (1994) Setting up and Running a School Library. Heinemann Education Publishers: Nairobi.

[2] Benkley; Y (2006).The Wealth of Network. Yale University Press: New Haven.

[3] Coombs, P. et. al (1976) Managing Education Costs. Oxford, NewYork.

[4] Farrant, J.S. (1980). Principles and Practice of Education. Longman Group Ltd: London:

[5] Gorman, E.G. and Howes, R.B (1991). Collection Development for Libraries.Biddles Limited, Guldford and King's Lynn, London.

[6] Jones, D, J. (2010) Uniting a Profession, Library Service. London

[7] Nafukho, F. M et al (2005) Foundation of adult Education in Africa Pearson Education South Africa. Cape Town.

[8] McColvin, (1978) The Demand Book Theory. Librarian Associations, LondonOluoch, G. P. (2002) Essentials of Curriculum: Development. Elimu Bookshop Ltd,Nairobi:

[9] Wikipedia (2009) Learning Reference Centres: Available at http/www. 